Air Force Coastal Command for the dropping of plastic drift envelopes into the Atlantic Ocean to the west of the British Isles, with the object of discovering seasonal changes in the speed and direction of the ocean currents which are believed to carry oil patches to the beaches of Britain (see Nature, October 24, 1953, p. 750). A reward of half-a-crown will be paid to the sender of each postcard (contained within the envelope), which is returned to the National Institute of Oceanography, Wormley, near Godalming, Surrey, with the simple questionnaire which is printed upon it filled in. Weather permitting, aircraft of Coastal Command, each carrying a scientist from the Institute, will make the first flights on January 20, and further flights will be made during the spring, summer and autumn. The dropping track on this winter flight will extend in a rough semi-circle from the centre of the Bay of Biscay to half-way between the north of Scotland and Iceland, the total length of the track being some 2,100 miles. The speed of the aircraft will average about $150 \mathrm{~m} . \mathrm{p} . \mathrm{h}$., and the envelopes will be dropped in bundles of ten, secured with gummed paper strip which will detach itself after a short time in the sea, the rate of dropping being such as to give an average of one envelope a mile. The envelopes in each bundle will be dispersed over a wide area before they reach tidal waters. It is expected that the first of the envelopes will strand during the middle of March, but their date of arrival will depend very largely on the wind during the time they are afloat. Arrangements have also been made with the Meteorological Office and the Netherlands Weathership Commission for Ocean Weather Ships at Stations "India"' $\left(61^{\circ} \mathrm{N} ., 15^{\circ} 20^{\prime} \mathrm{W}\right.$.) and "Juliett" $\left(52^{\circ} 30^{\prime} \mathrm{N} ., 20^{\circ} \mathrm{W}\right.$.) to drop one plastic envelope at noon each day throughout this year.

\section{Radioactive Corticosterone}

A NUMBer of Federal, university and private organizations in the United States have collaborated, with funds supplied by the National Institute of Arthritis and Metabolic Diseases of the United States Public Health Service, to produce a limited supply of redioactive corticosterone (compound B), which is now available to qualified investigators, free of charge. Last July, radioactive cortisone acetate and hydrocortisone were made available (see Nature, $172,187 ; 1953)$, and now, in conjunction with the latest announcement, supplies can be obtained of the following intermediates in the synthesis of cortisone acetate : pregnane-3,11,20-trione ; $3 \alpha, 17 \alpha$-dihydroxypregnane,11,20-dione; and 17, hydroxy-21-acetoxypregnane,3,11,20-trione. In addition, microcurie samples are available of $3 \alpha, 17 \alpha$-dihydroxy-21-acetoxypregnane,11,20-dione and $3 \alpha$,acetoxypregnane, 11,20-dione. All these compounds are labelled with carbon-14 at position 4 , and have a specific activity of $0.49 \mathrm{mc} . / \mathrm{m}$.mole, except the corticosterone, which has a specific activity of $1.47 \mathrm{mc} . / \mathrm{m}$.mole. Cortisone acetate, identically labelled, having a specific activity of approximately a third that of the activity previously announced for cortisone acetate, can also be obtained. Requests for any of the compounds should be made in the form of a letter, describing precisely the proposed research, and sent to the Endocrinology Study Section, Division of Research Grants, National Institutes of Health, Bethesda 14, Maryland. The transfer and use of these materials are subject to current regulations of the United States Atomic Energy Commission.

\section{The Society for Analytical Chemistry}

Ar an extraordinary general meeting of the Society of Public Analysts and Other Analytical Chemists, held in London on December 17, 1953, the name of the Society was changed to the Society for Analyticel Chemistry. The existence of this body dates back to its founding at a meeting held on August 7, 1874, when it was named the Society of Public Analysts, membership being restricted to practising public analysts and their assistants. But in course of time analytical chemists other than public analysts were also admitted as members, and on August 7, 1907, when the Society was incorporated, its extended membership was recognized by the adoption of the title of the Society of Public Analysts and Other Analytical Chemists. To-day the Society has far outgrown its original purpose of looking after the professional needs of the public analysts, which are now well served by the newly. formed Association of Public Analysts; the new Association is receiving the full support of the Society, financial and otherwise. The developments in analytical chemistry have been vast and striking during this century, but, although the Society's interest now extends over the whole range of natural and manufactured products, there will still be the same platform for the discussion of investigations into the composition of food and drugs. Indeed, it is intended that the character of The Analyst and of the ordinary meetings of the Society will be maintained unchanged, and that the Society will continue in its original aim of encouraging, assisting and extending the knowledge and study of all questions relating to the analysis, nature and composition of natural and manufactured materials generally. So as to encourage young chemists, the Society is starting a class of junior membership for those aged between eighteen and twenty-seven years; junior members will pay a considerably reduced subscription and no entrance fee, will receive The Analyst, and have the privilege of attending meetings.

\section{Optica Acta : New European Journal of Optics}

UNDER the ægis of the optical committees existing in various European countries, a new journal of optics will be appearing shortly, with the title Optica Acta. The aim is to provide in Europe a medium of publication for optical papers similar in scope and character to those which in the United States have their outlet in the Journal of the Optical Society of America. Optica Acta will be published in Paris by the Société de la Revue d'Optique under the direction of a board of control the thirteen members of which are leading optical research workers drawn from some seven countries, with Prof. J. M. Otero, of Madrid, as chairman. Further details can be obtained from the Assistant Secretary, Royal Society, Burlington House, London, W.1, who is also acting as collector for subscriptions in the United Kingdom.

\section{Histochemistry and Cytochemistry in the Univer- sity of Minnesota}

Is the recently completed Lyon Laboratory Building of the University of Minnesota Medical School, an entire floor has been especially designed for studies of quantitative histochemistry and cytochemistry under the direction of Prof. David Glick, professor of physiological chemistry in the University. The funds for the construction of this accommodation have been provided by the National Heart Institute 